\title{
36
}

\section{Discussion Group 4 - IT education delivery and learning}

\author{
Chair: Bernard Cornu (France)
}

Rapporteur: Peter Juliff (Australia)

Participants: Raphael Benza (Zimbabwe), Kristina Ekmark (Sweden), Peter Kanengoni (Zimbabwe), Olivia Magaya (Zimbabwe), Rudo Mataranyika (Zimbabwe), Babongile Moyo (Zimbabwe), Rosalie Mitchell (New Zealand), Leonadr Nhembe (Zimbabwe), Nyalugwe Nyalugwe (Zimbabwe), Karen Norwood (USA), Tomás O'Briain (Ireland), Heimir Palsson (Iceland), Shadreck Phiri (Zimbabwe), Faith Samkange (Zimbabwe), Chaweewan Sawetamalya (Thailand), Erling Schmidt (Denmark), Alpheas Shindi (Zimbabwe), Naume Sonhera (Zimbabwe), Lorainne Tafira (Zimbabwe), Alex Tigere (Zimbabwe)

\section{INTRODUCTION}

The aim of the discussion group was to examine the effects of Information and Communication Technologies (ICT) on the process of learning and the delivery of education. The majority of the group members were involved in education at primary and secondary levels, and the discussion was mainly centered around the issues relating to education at those levels. The focus of the group was the issues relating to the use of computer-related technology in the teaching and learning process, with particular emphasis on the problems encountered in developing countries.

\section{KEY ISSUES}

In keeping with the theme of the conference, the major questions addressed were :

- the difficulties involved in planning and investing in ICT in education to ensure maximum efficiency and effectiveness;

- the reasons underlying possible under-utilisation of ICT resources;

- lessons to be learned from other countries in the effective adoption of ICT in education;

- remedies available to overcome perceived difficulties;

Capacity Building for IT in Education in Developing Countries

G. Marshall \& M. Ruohonen (Eds.)

(c) 1998 IFIP. Published by Chapman \& Hall 
- the roles to be played by the IFIP community, governments and the private sector in providing a successful outcome to the introduction of ICT into the educational framework.

Three main themes emerged from the group discussion :

- issues relating to the integration of ICT within the broad spectrum of the educational curriculum;

- issues relating specifically to teachers;

- issues relating to the general learning process.

This record of the discussion will attempt to draw together the concerns expressed by members of the group, their experiences in teaching within their own environments, and their suggestions and recommendations on the solution to the problems which were encountered.

\section{THE EDUCATIONAL FRAMEWORK}

Despite their varied backgrounds, the members of the group portrayed a common environment in which they worked. The factors influencing their educational processes were:

- varying degrees of success in attempting to integrate ICT with other areas of the curriculum;

- mixed levels of computer literacy among teaching staff;

- difficulty in obtaining suitable levels of ICT teaching resources;

- a variety of levels of officially centralised control of syllabuses among the countries represented but at least an unofficial commonality due to the use of common software and common textbooks.

Concern was expressed by representatives of countries where English was not their native language that the adoption of English as the lingua franca of Information Technology was seen as having an undesirable effect on the use of the students' native language.

\section{4 \\ INTEGRATING IT WITHIN THE GENERAL CURRICULUM}

There is a need both to integrate ICT within the broad spectrum of the educational curriculum and to enable students who wish to do so to pursue specialist studies in that area. Specialisation, however, should be restricted to the last one or two years of the secondary curriculum. The majority of problems associated with the introduction of ICT into primary and secondary education will therefore be associated with its integration across other subject areas.

Integration in this sense refers to computer-based activities which both fulfill the aims of the subject being taught and assist in the acquisition of ICT skills.

Difficulties arise primarily as a result of the lack of appropriate skills on the part of teachers. It is also true that teachers tend to be conservative and to use the same teaching methods as those by which they themselves were taught. If teachers are to pursue the integration of subject matter and ICT, they must be provided with 
adequate access to appropriate resources. In most cases, this will involve a ranking of a school's priorities to allow sufficient importance to be given to computing resources. This in turn will extend to the political and economic policies set by governments - upon which most education depends.

The utilisation of computing resources must ultimately depend on the judgement of the teaching staff. There must not be engendered an attitude that these resources are under-utilised if they are not fully occupied each hour of the day.

To achieve effective integration of ICT within the curriculum, attention must be given to :

- the design of an imaginative curriculum which encourages teaching by 'entrepreneurial' techniques;

- adequate time allocation to teachers to devise new approaches to their activities;

- $\quad$ appropriate training for teachers to equip them with ICT skills sufficient for the task;

- adequate access to physical resources to be able to develop the necessary courseware.

Teachers need to actively communicate with one another to share skills and experience. This may be done partly by changing teacher training programs but may also be fostered by programmes involving team work and by skilled teachers acting in a mentor capacity for those less skilled.

In addition to the question of curriculum integration, there is also the question of integration with the community-at-large. Students will eventually wish to enter the workforce and the ICT skills acquired at school will play a large part in equipping them with life skills for later use.

Teachers need to regard themselves as agents of the transfer of ICT skills and knowledge. This may mean that they need to be prepared to abandon some timehonoured teaching practices. In turn, this means that they must be given adequate time to retrain and acquire new skills.

Once having acquired the skills needed for these activities, teachers must be given sufficient incentives to remain in the education system. The high turnover associated with the exodus of ICT-skilled teachers into the general workforce leads to discontinuity in the education process. Incentives may be in the form of increased remuneration or time release to pursue further relevant study.

Teachers must adopt the attitude that ICT resources are not solely for the use of computing studies students. This must be aided by the provision of a level of physical resources which ensures that adequate access is available for all students studying all subjects. The computer laboratory must be placed in the same category as the library, i.e., a general resource for all students and staff.

Teacher education needs to expand to ensure that disciplinary teaching methods embrace the means of using computer-based technology in the delivery of the subject matter. This policy must extend beyond the initial teacher training regimen 
to the re-education of existing teachers. There is an argument for making ICT education a mandatory component for graduation in any teacher education program.

The major inhibiting factors in the ICT learning process are closely related to issues already discussed above. Resources are in short supply, leading to frustration among students wishing to improve their skills. Teaching practices often do not encourage students to be innovative in their use of ICT. Existing computing resources are often seen as either the province of computing studies students or as prestigious acquisitions not to be placed at risk by the depredations of unskilled students. One possible means of alleviating the shortage of resources may be to accept equipment which has become surplus to the requirements of business organisations.

The greatest return from the use of ICT in the teaching and learning process occurs when the learning program is interactive rather than one-way and passive. Such interactive programs, however, take time, skill and imagination to develop. These are the very resources likely to be, at least initially, in the shortest supply among existing teaching staff.

Despite the associated difficulties, the scene is changing for the better. The use of pilot projects as exemplars is showing teachers what is possible. More educational software is being developed and is becoming widely available at what is claimed to be affordable prices. Unfortunately, 'affordable' is a subjective quality. Most developing countries are struggling to provide equipment resources and many lack even the commonly-accepted infrastructure of reliable power and telephone communications.

The growth of innovative learning programmes depends on the education or reeducation of all sectors of the educational hierarchy. Many teachers complain of inadequate allocation of time, money and equipment resources from principals who themselves have little empathy with the teachers' aims and visions.

The role of IFIP in the IT educational process is seen as largely one of a facilitator. The international nature of IFIP equips it to facilitate such activities as :

- sharing expertise and experience across national, cultural and economic boundaries;

- enabling dialogue between the worlds of education and commerce to better equip educators to prepare students for the vocational component of their life;

- promoting standards and common practices, and enabling dialogue among educators worldwide;

- encouraging government agencies to formulate education policies which promote innovation in curricula.

The conference from which this paper emanates is an example of such an enabling policy and the discussion of which this is a record is the result of much 
deliberation and sharing of ideas and experience from representatives of ten countries.

\section{$8 \quad$ CONCLUSION}

There is a need for educators to strike a balance between the pursuit of technology for its own sake and ignoring it as irrelevant to the essential pedagogical process of equipping students for a useful and rewarding life. There is also a need for balance between a feeling of guilt if technology does not pervade all aspects of a teacher's activities and adopting an attitude that change is not necessary.

Teachers and students, like the population at large, will adopt change and innovation if it is shown to be useful, enjoyable and nonthreatening. All of this takes time and resources. Schools must be given resources appropriate to the expectations of the staff and students. Teachers must be given time to take advantage of those resources. Given these prerequisites, the natural curiosity and enthusiasm of students will ensure that computer-based technology will be embraced as enhancing their education process and preparing them for a world in which these skills are becoming increasingly essential. 